\title{
CINÉTICA DA ADSORÇÃO DE ÍONS CÁDMIO EM PARTÍCULAS DE SERICINA/ALGINATO
}

\author{
M. F. RAGASSI ${ }^{1}$, J. O. de LIMA ${ }^{1}$, M. L. GIMENES ${ }^{2}$, M. G. C. da $\operatorname{SILVA}^{1}$ e M. G. A. \\ VIEIRA $^{1}$ \\ ${ }^{1}$ Universidade Estadual de Campinas, Faculdade de Engenharia Química \\ ${ }^{2}$ Universidade Estadual de Maringá, Departamento de Engenharia Química \\ E-mail para contato: mari.ragassi@hotmail.com
}

\begin{abstract}
RESUMO - A sericina é uma proteína presente no casulo do bicho-da-seda, geralmente descartada em efluentes de processos de fiação. $\mathrm{O}$ uso de alginato na formação de blenda com essa proteína visa melhorar as características físicas das partículas de sericina/alginato. $\mathrm{O}$ objetivo deste estudo foi investigar o uso de partículas de sericina/alginato como um bioadsorvente para a remoção de íons cádmio $\left(\mathrm{Cd}^{2+}\right)$ de águas residuais, por meio de estudo cinético de adsorção. Os modelos de pseudoprimeira ordem, pseudosegunda ordem e difusão intrapartícula foram ajustados aos dados experimentais. Os resultados mostraram que quanto maior a concentração inicial de $\mathrm{Cd}^{2+}$, maior a capacidade de adsorção no equilíbrio. Além disso, o modelo de pseudoprimeira ordem forneceu melhores coeficientes de correlação, indicando que a adsorção de $\mathrm{Cd}^{2+}$ em partículas de sericina/alginato segue este modelo. A partir do ajuste do modelo de difusão intrapartícula, verificou-se que a difusão no interior da partícula não é a única etapa que controla o processo de transferência de massa. A etapa de adsorção na superfície externa também influencia o processo. O biomaterial se mostrou eficiente, pois em apenas 120 minutos, a remoção de íons de $\mathrm{Cd}^{2+}$ alcançou o equilíbrio.
\end{abstract}

\section{INTRODUÇÃO}

Os metais tóxicos podem alcançar os cursos d'água naturalmente por meio de processos geoquímicos ou pela descarga direta de efluentes urbanos e industriais. Em concentrações elevadas, compostos metálicos solúveis, como o cádmio $(\mathrm{Cd})$, metal muito utilizado na produção de baterias níquel-cádmio, podem ser prejudiciais tanto para a saúde humana quanto para ambientes aquáticos e marinhos (Semerjian, 2010). Devido aos efeitos adversos, agências reguladoras têm promulgado normas cada vez mais restritivas em relação aos padrões de lançamento de efluentes.

Os métodos convencionais para a remoção de íons metálicos tóxicos de águas residuais como a precipitação e a adsorção em carvão ativado podem ser ineficazes ou extremamente caros para baixas concentrações de metais (Agrawal e Sahu, 2006), motivando, assim, a busca por novas tecnologias, tais como a bioadsorção. Esta biotecnologia é baseada na capacidade de ligação dos metais com vários materiais biológicos, que surge como alternativa, principalmente quando são utilizados adsorventes não convencionais de baixo custo, tais 


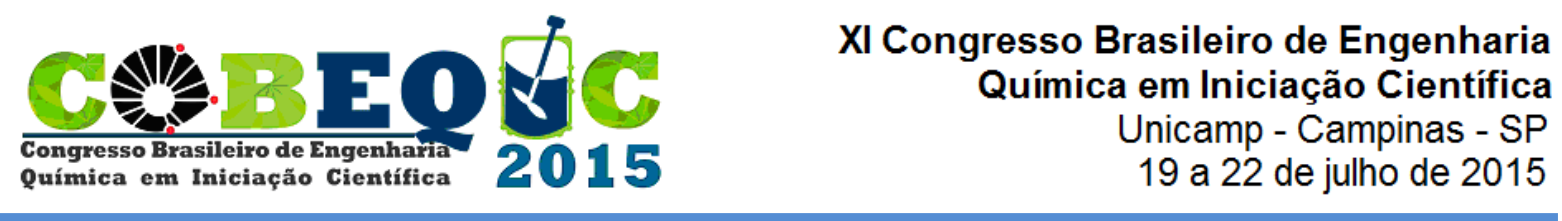

como resíduos de operações industriais, como é o caso da sericina, descartada no processamento da seda.

A sericina, proteína que constitui de 20 a $30 \%$ da massa total de casulos do bicho-daseda, possui aminoácidos com fortes grupos polares tais como hidroxila, carboxila e grupos amino. Estes grupos permitem a reticulação, copolimerização e formação de blendas com outros polímeros, como o alginato, de modo a melhorar suas características, uma vez que a sericina apresenta fracas propriedades estruturais e alta solubilidade em água (Zhang, 2002). $\mathrm{O}$ alginato é um polissacarídeo de fácil obtenção, por ser proveniente de fontes naturais, renováveis e abundantes, como algas marrons e bactérias, e é importante por ser biodegradável e ter boa biocompatibilidade (Nitã et al., 2007).

Portanto, o objetivo deste trabalho foi investigar o uso de partículas de sericina/alginato como bioadsorvente para a remoção de $\mathrm{Cd}^{2+}$ de águas residuais. Ensaios de adsorção foram realizados para o estudo cinético da remoção desse cátion, verificando-se a influência de sua concentração inicial. Os modelos cinéticos de pseudoprimeira ordem, pseudossegunda ordem e difusão intrapartícula foram utilizados para avaliar os mecanismos de adsorção.

\section{MATERIAIS E MÉTODOS}

\subsection{Preparação das Partículas}

Para a obtenção da sericina, utilizou-se casulos da espécie Bombyx Mori L., fornecidos pela Bratac S/A (Brasil). Os casulos foram limpos, cortados em partes de $1 \mathrm{~cm}^{2}$, lavados e mantidos em estufa a $50{ }^{\circ} \mathrm{C}$ durante 24 horas para que alcançassem massa constante. Em seguida, procedeu-se a etapa de extração, em que os casulos secos foram inseridos em Erlenmeyer com água destilada numa proporção de $4 \mathrm{~g}$ de casulos para $100 \mathrm{~mL}$ de água (4:100). O Erlenmeyer vedado foi colocado em uma autoclave (Phoenix Luterco, AV-18, Brasil) a uma pressão de $1 \mathrm{kgf} / \mathrm{cm}^{2}\left(\mathrm{~T}=120^{\circ} \mathrm{C}\right)$ durante 40 minutos. Após esse tempo, filtrou-se a quente a solução obtida e então, transferiu-se o filtrado para uma garrafa, a qual permaneceu à temperatura ambiente $\left(25^{\circ} \mathrm{C}\right)$ por 24 horas.

Após a etapa de extração, foi realizada a etapa de fracionamento, na qual a solução foi acondicionada em congelador convencional por 24 horas, e posteriormente descongelada a temperatura ambiente, ocorrendo a separação da fase que contém peptídeos de maior massa molar. A concentração da sericina foi determinada pelo método das massas e então ajustada para $25 \mathrm{~g} / \mathrm{L}(2,5 \% \mathrm{~m} / \mathrm{v})$. Para a obtenção da blenda, foi incorporado o alginato de sódio comercial (Sigma-Aldrich, Reino Unido) numa proporção de $2 \%(\mathrm{~m} / \mathrm{V})$ na solução ajustada de sericina, sob agitação constante. As partículas foram preparadas a partir da incorporação de cálcio na blenda por meio de seu gotejamento em uma solução aquosa $3 \%(\mathrm{~m} / \mathrm{v})$ de cloreto de cálcio $\left(\mathrm{CaCl}_{2}\right)$, também sob constante agitação. Para isso, utilizou-se uma bomba peristáltica (Masterflex L/S, 77800-60, EUA) à vazão constante.

Ao final deste processo, as partículas formadas foram mantidas em agitação constante na solução de cloreto de cálcio durante 12 horas a fim de finalizar o processo de reticulação. Posteriormente, as partículas foram secas à temperatura ambiente, e então mantidas em um forno de fluxo contínuo a $100{ }^{\circ} \mathrm{C}$ por 24 horas para que ocorresse a reticulação térmica, a fim de melhorar as propriedades mecânicas das partículas. 


\subsection{Cinética em Banho Finito}

Os experimentos de adsorção em banho finito foram realizados à temperatura ambiente $\left(25^{\circ} \mathrm{C}\right)$ com a adição de $7 \mathrm{~g}$ de partículas em $800 \mathrm{~mL}$ de soluções de cádmio com concentrações iniciais de 0,$5 ; 0,75$ e $1 \mathrm{mmol} / \mathrm{L}$, valores acima do limite imposto pelo Conama (Resolução $\mathrm{n}^{\circ} 430$ de 2011) para o cádmio total, que é de $0,00178 \mathrm{mmol} / \mathrm{L}$. As soluções sintéticas contendo o íon metálico foram preparadas pela dissolução do sal metálico $\mathrm{Cd}\left(\mathrm{NO}_{3}\right)_{2} \cdot 4 \mathrm{H}_{2} \mathrm{O}$ (Vetec, Brasil) em água ultra pura, obtida pelo sistema Milli-Q Academic (Millipore).

O sistema (solução e partículas) foi mantido sob agitação constante e, em intervalos de tempos pré-determinados, foram retiradas alíquotas de $2 \mathrm{~mL}$ da solução, as quais foram centrifugadas e o sobrenadante diluído para análise de concentração do cádmio por espectrofotometria, utilizando o Espectrofotômetro de Absorção Atômica (Perkin Elmer, AA100 , EUA). O pH foi mantido em torno de $6 \mathrm{em}$ todos os experimentos, valor abaixo do ponto de mínima precipitação para o cádmio, que de acordo com o diagrama de especiação química está em torno de 8 . Em pH 6, o cádmio aparece predominantemente como espécies de $\mathrm{Cd}^{2+}$ na solução, evitando que a formação de complexos ou precipitação de hidróxidos impeçam a adsorção de cádmio nas partículas de sericina/alginato.

A capacidade de adsorção é expressa como a quantidade de íon metálico adsorvido por unidade de massa de partícula empregando a Equação 1:

$$
q=\frac{\left(C_{0}-C\right) V}{m}
$$

em que: $q$ - capacidade de adsorção (mmol/g), $C_{0}$ e $C$ - concentrações inicial e residual do íon metálico (mmol/L), $V$ - volume da solução metálica (L) e $m$ - massa do bioadsorvente $(\mathrm{g})$.

\subsection{Modelos Cinéticos}

Para determinar os mecanismos da adsorção de $\mathrm{Cd}^{2+}$ por partículas de sericina/alginato, os seguintes modelos cinéticos foram empregados neste trabalho:

Modelo de pseudoprimeira ordem: Modelo cinético representado pela equação de Lagergren que descreve a adsorção em sistemas sólido-líquido baseada na capacidade de adsorção dos sólidos (Ho, 2004). Assume-se que um íon metálico é adsorvido em um sítio de adsorção na superfície do adsorvente e é expresso pela Equação 2:

$$
q=q_{e}\left(1-e^{-K_{1} t}\right)
$$

em que: $q_{e}$ é a capacidade de adsorção no equilíbrio $\left(m m o l . g^{-1}\right) ; q$ é a capacidade de adsorção em um tempo $\mathrm{t}\left(\mathrm{mmol} . \mathrm{g}^{-1}\right)$; $t$ é o tempo (min); e ${ }^{k_{1}}$ é a constante cinética de primeira ordem $\left(\mathrm{min}^{-1}\right)$.

Modelo de pseudossegunda ordem: Esse modelo tem sido aplicado para análise cinética de quimissorção de soluções líquidas (Ho, 2006). Assume-se que um íon metálico é adsorvido em dois sítios de adsorção na superfície do adsorvente e é expresso pela Equação 3: 


$$
\frac{q}{q_{e}}=\frac{K_{2} q_{e} t}{\left(1+K_{2} q_{e} t\right)}
$$

em que: ${ }_{2}$ é a constante cinética de segunda ordem $\left(\mathrm{g} \cdot \mathrm{mmol}^{-1} \cdot \mathrm{min}^{-1}\right)$.

Modelo de difusão intrapartícula: De acordo com a teoria proposta por Weber e Morris (1963), o modelo de difusão intrapartícula é expresso pela Equação 4:

$$
q=k_{i} t^{1 / 2}+c
$$

em que: $k_{i}$ é a constante de difusão intrapartícula $\left(m m o l \cdot g^{-1} \cdot m^{-0,5}\right)$ e $c$ é uma aproximação da espessura da camada limite.

\section{RESULTADOS E DISCUSSÃO}

Os modelos cinéticos de pseudoprimeira ordem, pseudosegunda ordem e difusão intrapartícula foram ajustados aos dados experimentais a fim de se compreender a cinética de remoção de $\mathrm{Cd}^{2+}$ por partículas de sericina/alginato. Os resultados encontram-se na Figura 1.

Figura 1 - Curvas cinéticas e ajuste dos modelos de pseudoprimeira e pseudossegunda ordem (a) e difusão intrapartícula (b) para adsorção de $\mathrm{Cd}^{2+}$ em partículas de sericina/alginato.
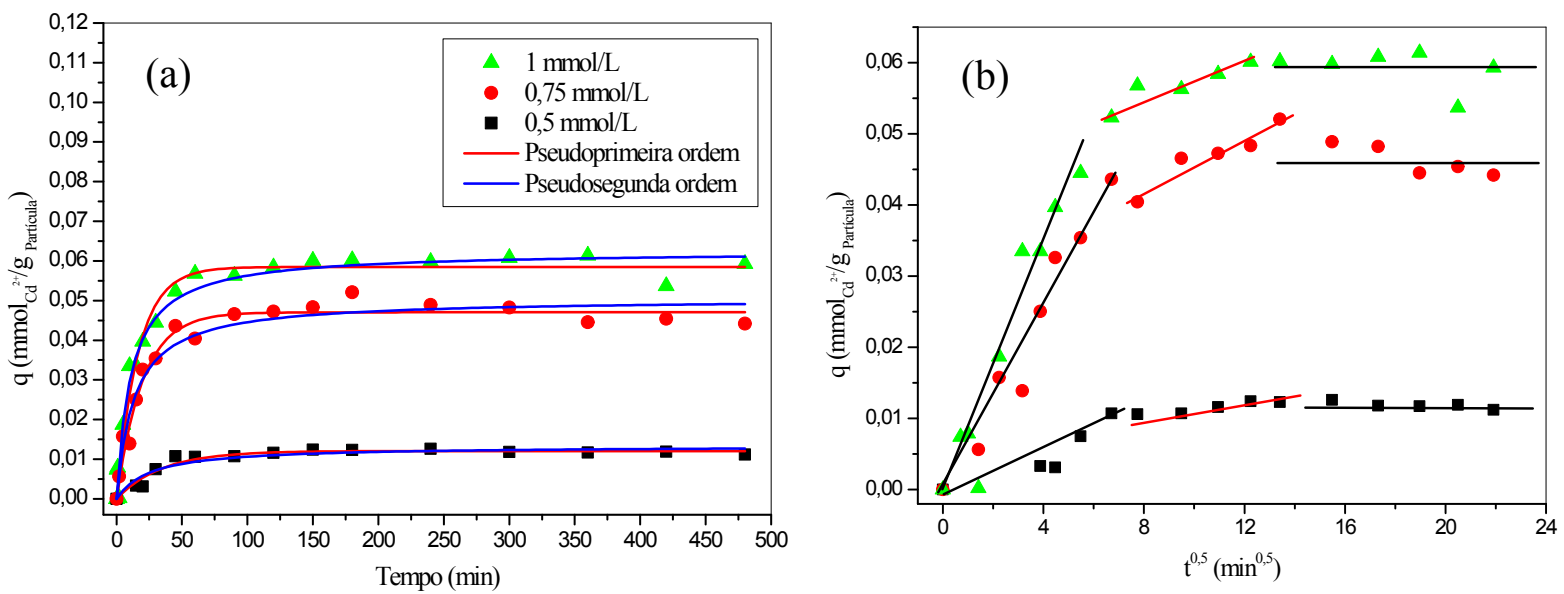

A partir da Figura 1(a), observa-se que as três curvas apresentam comportamento similar, o que pode ser comprovado pelo formato das mesmas. Verifica-se também que, quanto maior a concentração inicial de $\mathrm{Cd}^{2+}$, maior a capacidade de adsorção desse cátion no equilíbrio $\left(\mathrm{q}_{\mathrm{e}}\right)$, o que pode ser explicado pelo fato de que com o aumento da concentração inicial, a força motriz de transferência de massa acelera a difusão do $\mathrm{Cd}^{2+}$ da solução para o adsorvente, resultando em uma maior capacidade de adsorção.

Em relação ao tempo de contato no processo de adsorção, verifica-se que o tempo para atingir o equilíbrio variou de acordo com a concentração inicial de cádmio: aproximadamente $60 \min \left(\mathrm{C}_{0}=0,5 \mathrm{mmol} / \mathrm{L}\right), 90 \mathrm{~min}\left(\mathrm{C}_{0}=0,75 \mathrm{mmol} / \mathrm{L}\right)$ e $120 \mathrm{~min}\left(\mathrm{C}_{0}=1 \mathrm{mmol} / \mathrm{L}\right)$. Ou seja, houve uma rápida captação inicial de íons de cádmio, o que pode ser devido ao fato de que 
inicialmente, todos os sítios na superfície do adsorvente estavam vazios e o gradiente de concentração do soluto é relativamente elevado. Após os tempos citados, a taxa de adsorção tornou-se praticamente constante, devido à saturação dos sítios de adsorção do adsorvente.

O gráfico da difusão intrapartícula, como mostrado na Figura 1(b), mostra um comportamento multilinear, indicando que a difusão no interior da partícula não é a única etapa que controla o processo de transferência de massa. Três etapas estão envolvidas no processo de adsorção: a primeira seção linear é a adsorção na superfície externa; a segunda etapa descreve a adsorção gradual do $\mathrm{Cd}^{2+}$, na qual a difusão intrapartícula é o mecanismo limitante do processo de adsorção. A última etapa é o estado de equilíbrio dinâmico entre a adsorção e dessorção do adsorbato. Os parâmetros obtidos por meio de ajuste não linear para as três concentrações iniciais de cádmio de acordo com os modelos propostos estão sumarizados na Tabela 1.

Tabela 1 - Parâmetros cinéticos para os modelos de pseudoprimeira ordem, pseudossegunda ordem e difusão intrapartícula para a bioadsorção de $\mathrm{Cd}^{2+}$ em partículas de sericina/alginato.

\begin{tabular}{|c|c|c|c|c|}
\hline \multirow{3}{*}{ Modelo } & \multirow{2}{*}{ Parâmetro } & \multicolumn{3}{|c|}{ Concentração Inicial (mmol/L) } \\
\hline & & 0,5 & 0,75 & 1,0 \\
\hline & $\begin{array}{c}\mathrm{q}_{\mathrm{e}} \text { experimental } \\
(\mathrm{mmol} / \mathrm{g})\end{array}$ & $\mathbf{0 , 0 1 1 8}$ & 0,0462 & $\mathbf{0 , 0 5 9 0}$ \\
\hline \multirow{3}{*}{$\begin{array}{c}\text { Pseudoprimeira } \\
\text { ordem }\end{array}$} & $\mathrm{q}_{\mathrm{e}}\left(\mathrm{mmol} \cdot \mathrm{g}^{-1}\right)$ & 0,0120 & 0,0470 & 0,0584 \\
\hline & $\mathrm{k}_{1}\left(\min ^{-1}\right)$ & 0,0289 & 0,0504 & 0,0605 \\
\hline & $\mathrm{R}^{2}$ & 0,9432 & 0,9693 & 0,9742 \\
\hline \multirow{3}{*}{$\begin{array}{c}\text { Pseudossegunda } \\
\text { ordem }\end{array}$} & $\mathrm{q}_{\mathrm{e}}\left(\mathrm{mmol} . \mathrm{g}^{-1}\right)$ & 0,0133 & 0,0505 & 0,0625 \\
\hline & $\mathrm{k}_{2}\left(\mathrm{~g} \cdot \mathrm{mmol}^{-1} \cdot \mathrm{min}^{-1}\right)$ & 2,8947 & 1,4745 & 1,4492 \\
\hline & $\mathrm{R}^{2}$ & 0,8942 & 0,9552 & 0,9751 \\
\hline \multirow{3}{*}{$\begin{array}{c}\text { Difusão } \\
\text { Intrapartícula }\end{array}$} & $\mathrm{k}_{\mathrm{i}}\left(\mathrm{mmol} \cdot \mathrm{g}^{-1} \cdot \mathrm{min}^{-0,5}\right)$ & 0,00036 & 0,00179 & 0,00117 \\
\hline & $\mathrm{c}\left(\mathrm{mmol} . \mathrm{g}^{-1}\right)$ & 0,00764 & 0,02763 & 0,04577 \\
\hline & $\mathrm{R}^{2}$ & 0,8588 & 0,8769 & 0,7657 \\
\hline
\end{tabular}

Pode ser observado da Tabela 1 que os valores de $\mathrm{q}_{\mathrm{e}}$ calculados pelos modelos mostram uma boa concordância com os valores experimentais, o que indica que os modelos cinéticos de pseudoprimeira e pseudossegunda ordem descrevem bem a remoção de $\mathrm{Cd}^{2+}$ utilizando as partículas de sericina/alginato em estudo. Com base no $\mathrm{R}^{2}$, verificou-se que a equação de pseudoprimeira ordem ajustou melhor os dados experimentais, o que significa que a adsorção de $\mathrm{Cd}^{2+}$ nas partículas avaliadas é adsorção em monocamada, típica de adsorção química. Porpino (2009) estudou a bioadsorção de ferro (II) por casca de caranguejo e também obteve que o modelo de pseudoprimeira ordem foi o melhor para descrever esse processo. A constante cinética $\mathrm{k}_{1}$ é uma função linear da concentração inicial do íon metálico $\left(\mathrm{C}_{0}\right)$, o que justifica o fato dessa aumentar de acordo com a concentração.

De acordo com a Tabela 1, constata-se que o valor da constante $c$ é maior conforme o aumento da concentração inicial de cádmio, o que representa o aumento da espessura da camada limite e, consequentemente, o aumento da resistência à transferência de massa externa, de modo que a difusão superficial torna-se uma etapa limitante deste processo. 


\section{CONCLUSÕES}

Os ensaios cinéticos de adsorção do $\mathrm{Cd}^{2+}$ em partículas de sericina/alginato para diferentes concentrações iniciais desse íon metálico indicaram que a adsorção é dependente deste parâmetro, mostrando que quanto maior a concentração maior a capacidade de adsorção no equilíbrio. Verificou-se também que a equação de pseudoprimeira ordem forneceu os melhores ajustes dos dados experimentais, o que significa que a adsorção de $\mathrm{Cd}^{2+}$ nas partículas ocorre em monocamada. Em relação ao ajuste do modelo de difusão intrapartícula verificou-se uma multilinearidade, indicando tanto a etapa de difusão no interior da partícula quanto a etapa de adsorção na superfície externa controlam o processo de transferência de massa. Este material se mostrou eficiente e apresentou potencial de aplicação para a remoção de íons de cádmio de soluções aquosas. Nas condições avaliadas, 120 minutos foram considerados suficientes para o equilíbrio do processo.

\section{REFERÊNCIAS}

AGRAWAL, A; SAHU, K. K. Kinetic and isotherm studies of cadmium adsorption on manganese nodule residue. J. Hazard. Mater., v. 137, p. 915-924, 2006.

HO, Y. S. Citation review of Lagergren kinetic rate equation on adsorption reactions. Scientometrics, v. 59, p. 171-177, 2004.

HO, Y. S. Review of second-order models for adsorption systems. J. Hazard. Mater., v. 136, p. 681-689, 2006.

NITÃ, I.; IORGUlESCU, M.; SPIROIU, M. F.; GHIUREA, M.; PETCU, C.; CINTEZÃ, O. The adsorption of heavy metal ions on porous calcium alginate microparticles. Analele Universitatii din Bucuresti, Anul XVI, v. 1, p. 59-67, 2007.

PORPINO, K. K. P. Biossorção de ferro (II) por casca de caranguejo Ucides Cordatus. João Pessoa: Departamento de Química, Universidade Federal da Paraíba, 2009. 93p. Dissertação de Mestrado.

SEMERJIAN, L. Equilibrium and kinetics of cadmium adsorption from aqueous solutions using untreated Pinus halepensis sawdust. J. Hazard. Mater., v. 173, p. 236-242, 2010.

WEBER, W. J.; MORRIS, J. C. Kinetics of adsorption on carbon from solution. J. Sanit. Eng. Div., v. 89, p. 31-59, 1963.

ZHANG, Y. Q. Applications of natural silk protein sericina in biomaterials. Biothechnology Advances, v. 20, p. 91-100, 2002.

\section{AGRADECIMENTOS}

Os autores agradecem ao CNPq e à FAPESP pelo apoio financeiro. 